\title{
Keanekaragaman Jenis Reptilia di Kecamatan Seginim Kabupaten Bengkulu Selatan
}

\section{Diversity Of Reptile Species Found In District Seginim Bengkulu Selatan}

\author{
Pariyanto $^{1}$, Rahmi $^{2 *}$, Dindi Antarsyah ${ }^{1}$
}

${ }^{1}$ Program Studi Pendidikan Biologi Universitas Muhammadiyah Bengkulu, ${ }^{2}$ Program Studi Pendidikan Biologi Universitas Riau Kepulauan Batam. *Correspondent email : rahmikumbang@ gmail.com

Received: 11 June 2020 | Accepted: 30 July 2020 | Published: 3 August 2020

\begin{abstract}
Abstrak. Tujuan penelitian ini adalah mengetahui keanekaragaman jenis reptilia yang terdapat di Kecamatan Seginim Kabupaten Bengkulu Selatan Propinsi Bengkulu. Metode yang digunakan dalam penelitian ini adalah metode survei. Pengambilan sampel dilakukan dengan menjelajahi lokasi penelitian dan memasang perangkap serta menangkap secara langsung semua jenis reptilia yang ditemukan di lokasi penelitian. Pada penelitian ini ditemukan 10 spesies reptilian, yang termasuk ke dalam 2 ordo dan 8 famili, yaitu Ordo Squamata dan Ordo Terstudinata. Spesies yang termasuk ordo Squamata, famili Varanidae: Varanus salvator, famili Gekkonidae: Gekko gecko dan Hemidactylus frenatus, famili Colubridae: Ahaetulla prasina dan Dendrealaphis pictus, famili Pythonidae: Python reticulatus, famili Agamidae: Bronchocella cristatella, famili Xenopeltidae: Xenopeltis unicolar, dan famili Scincidae: Mabouya multifasciata. Spesies yang termasuk ordo Testudinata, famili Geoemydae: Siebenrockiella crassicollis. Indeks Keanekaragaman jenis hewan reptilian di lokasi penelitian sebesar 0,823, yang termasuk kategori rendahyang menunjukkan habitat dan populasi reptil di Kecamatan Seginim dalam keadaan tertekan dan tidak seimbang.

Kata Kunci : Bengkulu Selatan, Keanekaragaman, Kecamatan Seginim, Reptil.

Abstract. The purpose of this study was to determine the diversity of reptile species found in Seginim District, South Bengkulu Regency, Bengkulu Province. The method used in this study is a survey method. Sampling is done by exploring the research site and setting traps and capturing directly all types of reptiles found at the study site. In this study found 10 reptilian species, which belong to 2 orders and 8 families, namely Squamata and Terstudinata Orders, Species belonging to the order Squamata, Varanidae family: Varanus salvator, Gekkonidae family: Gekko gecko and Hemidactylus frenatus, Colubridae family: Ahaetulla prasina and Dendrealaphis pictus, Pythonidae amily: Python reticulatus, family Agamidae: Bronchocella cristatella, Xenopeltidae family: Xenopeltis unicolar, and Scincidae family: Mabouya multifasciata. Species belonging to the order Testudinata, family Geoemydae: Siebenrockiella crassicollis. The diversity index of reptilian animals at the study site was 0.823 , which is in the low category which shows the habitat and reptile population in the District of Seginim in a depressed and unbalanced state.

Keywords : South Bengkulu, Diversity, Seginim Sub district, Reptile.
\end{abstract}

\section{PENDAHULUAN}

Reptil merupakan sekelompok vertebrata yang merupakan hewan ectothermic dengan kata lain suhu tubuh hewan ini memiliki ketergantungan terhadap lingkungan yang ada disekitarnya (Ario, 2010). Reptil juga memiliki kemampuan untuk menyesuaikan diri di tempat yang kering di tanah. Ciri lain dari reptil adalah adanya penandukan atau cornificatio kulit dan squama atau carpace untuk menjaga banyak hilangannya cairan dari tubuh pada tempat yang kasar (Jasin,1984 dalam Findua et al., 2016).

Reptil terdiri dari ular, kadal cacing, kadal buaya, caiman, kura-kura, penyu, dan tuatara. Terdapat kurang lebih 7.900 spesies reptil yang ada sampai saat ini dan mendiami berbagai tipe habitat, seperti habitat yang memiliki iklim sedang maupun tropis termasuk, hutan, lahan basah, dan air tawar, hutan bakau dan laut terbuka (Campbell dan Reece, 2010). Penelitian mengenai 
reptilia sudah banyak dilakukan diantaranya oleh Lisa (2011) yang menemukan 9 jenis kadal di Bukit Sulap Kota Lubuk Linggau Provinsi Sumatera Selatan. Kawasan penelitian menunjukkan lokasi di daerah perkotaan dengan topografi yang menanjak ketinggian $471 \mathrm{~m}$ dpl. Amri et al., (2015) menemukan 10 jenis reptil di Hutan Lindung Gunung Semahung Desa Sebatih Kecamatan Sangeh Temila Kabupaten Landak Porpinsi Kalimantan Selatan. Rosadi et al., (2016) menemukan 7 jenis reptil di kawasan Taman Wisata Alam Bukit Kaba Kabupaten Rejang Lebong Provinsi Bengkulu. Selanjutnya Putra et al., (2017) menemukan 5 jenis reptil di kawasan Suaka Margasatwa Tanjung Santigi. Sedangkan Mumpuni (2001) dalam penelitiannya di Taman Nasional Gunung Halimun menemukan 21 jenis reptile.

Dengan mencermati penelitian yang telah dilakukan diberbagai tempat, pada setiap wilayah ditemukan reptil dengan jumlah yang berbeda-beda. Hewan reptil penting sebagai keseimbangan ekosistem dan perannya dalam rantai makanan. Oleh karena itu penting dilakukan penelitian serupa mengenai keanekaragaman reptil di Kecamatan Seginim Kabupaten Bengkulu Selatan.

Wilayah Seginim berada pada koordinat $4^{\circ} 21^{\prime} 32^{\prime \prime S} 103^{\circ} 02^{\prime} 4{ }^{\circ \prime} \mathrm{E}$, dengan topografi wilayah datar dan berbukit-bukit serta memiliki luas wilayah mencapai $61.52 \mathrm{Km}^{2}$, yang terdiri dari daerah persawahan, hutan skunder, perkebunan dan pemukiman penduduk (Pemerintah Kecamatan Seginim, 2018). Dengan kondisi geografis tersebut dan beragamnya habitat, sangat cocok untuk kehidupan reptil dan dimungkinan keanekaragaman reptil tinggi di kawasan ini. Berdasarkan hasil observasi awal yang dilakukan ditemukan berbagai jenis hewan reptil seperti kura- kura, ular, dan jenis kadal seperti tokek, cicak, biawak, bengkarung, dan bunglon. Namun demikian informasi mengenai indek keanekaragaman jenis reptil di Kecamatan Seginim Kabupaten Bengkulu Selatan, secara ilmiah belum diketahui secara pasti.

Untuk mengungkap keanekaragaman jenis reptil di wilayah Seginim perlu dilakukan penelitian untuk memperoleh informasi keanekaragaman jenis reptil yang dapat digunakan sebagai dasar pengelolaan lingkungan dan ekosistem khususnya terkait pengendalian rantai makanan. Tujuan penelitian ini adalah untuk mengetahui indeks keanekaragaman jenis reptilia yang terdapat di Kecamatan Seginim Kabupaten Bengkulu Selatan.

\section{METODE PENELITIAN}

Penelitian ini dilakukan pada bulan Januari sampai dengan bulan Maret tahun 2019 bertempat di Kecamatan Seginim Kabupaten Bengkulu Selatan, Propinsi Bengkulu. Alat dan bahan yang digunakan dalam penelitian ini adalah: buku panduan lapangan, thermohigrometer (mengukur suhu dan kelembaban udara), tali rafia, meteran (untuk mengukur jarak dan panjang reptile), pisau, penangkap ular, bubu (perangkap reptile), kantong dan tabung spesimen, alkohol $70 \%$ dan formalin4\% digunakan untuk mengawetkan spesimen, dan aquades $1000 \mathrm{ml}$; untuk pelarut, serta alat tulis.

\section{Teknik pengambilan data}

Metode yang digunakan dalam penelitian ini mengacu pada Yanuarefa et al., (2017) dengan survey langsung. Data reptile yang dicatat yaitu (1) nama jenis, (2) jumlah individu tiap jenis dan (3) habitat saat di lokasi. Pengumpulan data keanekaragaman jenis reptil dilakukan pada 4 lokasi yaitu, : (1). Danau Muara dengan luas jelajah 1 (satu) ha, (2). Persawahan seluas 5 ha, (3). Sungai seluas 1 (satu) ha dan (4). Kawasan hutan seluas 3 ha. Metode pengumpulan data 
dilakukan dengan menjelajahi lokasi dan memasang perangkap serta menangkap secara langsung semua jenis reptile yang ditemukan di lokasi penelitian. Pengamatan dilakukan pada siang hari dan malam hari. Pengamatan siang hari dimulai antara pukul 07.00 atau 08.00 sampai dengan 11.00 WIB, pengamatan malam antara pukul 19.00 sampai 23.00 WIB. Proses identifikasi mengacu Ario (2010), Irham (2012), dan Andin (2010).

\section{Analisis Data}

Data yang diperoleh dianalisis secara deskriptif kuantitatif dan analisis indeks keragaman jenis Shannon-Wiener merujuk Amri et al., (2015) dengan rumus sebagai berikut :

$$
\mathrm{H}^{1}=-\sum \frac{n i}{N} \log \frac{n i}{N}
$$

Dimana $\mathrm{H}=$ Indeks keanekaragaman jenis Shannon-Winner; $\mathrm{Ni}=$ Jumlah individu dari satu jenis I; dan $\mathrm{N}=$ Jumlah total individu seluruh jenis. Nilai indeks keanekaragaman jenis Shannon-Winner didefinisikan $\mathrm{H}^{\prime}>3=$ keanekaragaman spesies tinggi $1 \leq \mathrm{H}^{\prime} \leq 3=$ keanekaragaman spesies sedang; dan $\mathrm{H}^{\prime}<1=$ keanekaragaman spesies rendah.

\section{HASIL PENELITIAN}

Pada penelitian ini ditemukan 10 spesies reptil yang termasuk dalam 2 ordo dan 8 famili. Data spesies reptile yang ditemukan selama penelitian disajikan pada (Tabel 1.), data indeks keragaman jenis disajikan pada (Tabel 2.) dan data faktor abiotik disajikan pada (Tabel 3.). Tabel 1. Keanekaragaman hewan reptilia yang ditemukan di lokasi penelitian.

\begin{tabular}{|c|c|c|c|c|c|}
\hline No & Ordo & Famili & Spesies & Nama lokal & Jumlah \\
\hline \multirow[t]{9}{*}{1.} & Squamata & Varanidae & Varanus salvator & Biawak & 4 \\
\hline & & Gekkonidae & Gekko gecko & Tokek & 4 \\
\hline & & & Hemidactylus frenatus & Cecak kayu & 16 \\
\hline & & Colubridae & Ahaetulla prasina & Ular pucuk & 6 \\
\hline & & & Dendrealaphis pictus & Ular tambang & 9 \\
\hline & & Pythonidae & Python reticulates & Sanca kembang & 1 \\
\hline & & Agamidae & Bronchocella cristatella & Bunglon & 15 \\
\hline & & Xenopeltidae & Xinopeltis unicolar & Ular pelangi & 2 \\
\hline & & Scincidae & Mabouya mutifasciata & Kadal kebun & 20 \\
\hline 2. & Testudinata & Geoemydidae & Siebenrockiella crassicollis & Kura-kura & 2 \\
\hline \multicolumn{3}{|c|}{ Jumlah individu } & & & 79 \\
\hline
\end{tabular}

Reptil dari Famili Gekkonidae dan Colubridae masing-masing ditemukan 2 spesies, famili Gekkonidae yaitu Gekko gecko (Tokek) dan Hemidactylus frenatus (Cicak kayu), dan famili Colubridae yaitu Ahaetulla prasina (Ular pucuk) dan Dendrealaphis pictus (Ular tambang). Semua spesies dari famili Colubridae sebagian besar ditemukan di pepohonan, baik pohon mati maupun pohon yang masih hidup, ada juga yang ditemukan di lubang-lubang pohon. Spesies dari famili ini dapat beradaptasi dengan lingkungan hutan yang masih alami (primer) maupun yang sudah dikonversi menjadi hutan produksi. Kondisi ini sesuai dengan pernyataan Iskandar (2000) yang menyatakan bahwa famili Colubridae menempati habitat hutan primer, hutan sekunder dan pinggiran hutan. Karakter habitat di lokasi penelitian cocok untuk hewan famili Colubridae dan didukung oleh tersedianya makanan berupa serangga dan hewan kecil lainnya. 
Dari 2 ordo yang ditemukan di lokasi penelitian, ordo Squamata lebih banyak ditemukan dibandingkan ordo Testudinata. Ordo Squamata yang ditemukan 7 famili yang dominan ditemukan di hutan, lebih spesifik di atas pepohonan, di bawah kayu yang sudah lapuk, semak belukar, dekat aliran air, dan bahkan ada juga yang ditemukan di rawa-rawa. Menurut Pough (1998) ordo Squamata habiatnya mulai dari bawah tanah hingga pepohonan, kebanyakan ordo Squamata tinggal di atas tanah (terestarial) sementara sebagiannya hidup menyusup di tanah gembur atau pasir (fossorial).

Pada ordo Testudinata ditemukan 1 (satu) famili yaitu Geoemydidae dengan 1 (satu) spesies yaitu S. crassicollis (Kura-kura pipi putih). Temuan pada family Geoemydidae ini lebih sedikit diduga dikarenakan habitat yang sudah rusak dan tidak dapat mendukung kehidupan spesies dari famili ini. Kerusakan habitat seperti pengeringan rawa untuk lahan kebun sawit, dan perubahan persawahan menjadi perkebunan sayur-sayuran menyebabkan lahan menjadi kering. Iskandar (2000) menyatakan bahwa habitat kura-kura ditemukan di rawa, sungai, dan persawahan dengan keadan air selalu mengalir kekawasan tersebut. Aliran air yang tenang dan adanya tanaman air dapat menjadi makanan bagi spesies kura-kura. Selain kondisi habitat yang buruk, perburuan oleh masyarakat setempat terhadap spesies kura-kura cenderung meningkat untuk tujuan komersil dan dijadikan hiasan. Bebarapa penyebab menurunnya populasi spesies kura-kura dilaporkan oleh Martiva et al., (2016) yang menyatakan bahwa dalam beberapa tahun terakhir terjadi penurunan jumlah populasi kura-kura karena di perdagangkan, juga lambatnya populasi kura-kura untuk tumbuh dewasa.

Spesies paling banyak ditemukan selama penelitian ini adalah M. multifasciata (Kadal kebun), yaitu sebanyak 20 individu. Banyaknya populasi spesies ini diduga karena kondisi lingkungan sesuai dengan habitat kadal. Selama penelitian, spesies ini banyak ditemukan di tempat bersemak dan berumput, di pinggir-pinggir persawahan yang berumput dan di tumpukan serasah, baik ditempat terbuka maupun yang terlindung dengan oleh pepohonan. Ketersedian makanan yang melimpah bagi spesies ini seperti aneka serangga, cacing, kodok kecil (ampibi), dan juga hewan reptil lainnya seperti cecak dan jenis kadal lain yang bertubuh lebih kecil, menjadikan spesies ini berkembang dengan baik. Juniarmi dan Zakaria (2014) melaporkan bahwa $M$. multifasciata menyukai tempat yang di tutupi serasah daun yang terlindung oleh pohon. Semakin beranekaragam struktur habitat maka semakin besar populasi jenis hewan ini, dikarenakan sumberdaya yang cukup khususnya sebagai tempat mencari makan, berlindung dan berkembang biak. Sedangkan spesies yang paling sedikit ditemukan ialah Python reticulatus (Sanca kembang) ditemukan hanya 1 (satu) individu. P. reticulatus ditemukan di danau pada malam hari. Adanya perburuan terhadap ular phyton diduga telah menyebabkan sulitnya spesies ini ditemukan. Dugaan ini diperkuat oleh adanya informasi masyarakat sekitarnya bahwa ular jenis Sanca kembang banyak diburu untuk diambil kulitnya.

Jumlah individu hewan reptilia yang ditemukan di lokasi penelitian yaitu sebanyak 79 individu dengan nilai indeks keanekaragaman jenis dengan nilai $\mathrm{H}^{\prime}=0,823$. Keragaman jenis tertinggi terdapat pada $M$. multifasciata dengan indeks sebesar 0,150 , sedangkan indeks keragaman jenis yang terendah adalah $P$. reticulates dengan nilai 0,020 . Nilai indeks keanekaragaman jenis hewan reptilia di lokasi penelitian termasuk ke dalam katagori rendah. Hal ini mirip dengan laporan Subeno (2018) yang menyatakan bahawa keanekaragaman herpetofauna di Hulu Sungai Gunung Sindoro Jawa tengah diperoleh sebesar 1,03 yang berarti 
bahwa keragamannya rendah. Indek keragaman herpetofauna yang rendah juga dilaporkan sebelumnya pada Taman Nasional Gunung Merbabu (Subeno et at., 2010).

Tabel 2. Indeks keanekaragaman jenis reptil yang ditemukan di lokasi penelitian

\begin{tabular}{llccc}
\hline No & \multicolumn{1}{c}{ Nama Spesies } & Jumlah & KR & H' \\
\hline 1. & Varanus salvator & 4 & 0,05 & 0,065 \\
2. & Gekko gecko & 4 & 0,05 & 0,065 \\
3. & Hemidactylus frenatus & 16 & 0,20 & 0,139 \\
4 & Ahaetulla prasina & 6 & 0,07 & 0,080 \\
5. & Dendrealaphis pictus & 9 & 0,11 & 0,105 \\
6. & Python reticulates & 1 & 0,01 & 0,020 \\
7. & Bronchocella cristatella & 15 & 0,18 & 0,133 \\
8. & Xenopeltis unicolar & 2 & 0,02 & 0,033 \\
9. & Mabouya multifasciata & 20 & 0,25 & 0,150 \\
10. & Siebenrockiella crassicollis & 2 & 0,02 & 0,033 \\
\hline & Jumlah individu & 79 & & 0,823 \\
\hline
\end{tabular}

Letak suatu kawasan dan kondisi lingkungan sangat menentukan keanekaragaman spesies di dalamnya. Kawasan di Kecamatan Seginim Kabupaten Bengkulu Selatan sudah banyak yang terkonversi mejadi lahan pertanian (sawah, kebun, pemukiman). Adanaya perubahan lingkungan tersebut sangat mempengaruhi populasi reptil karena terjadinya perubahan faktor-faktor pembatas khususnya makanan dan habitat yang ideal untuk berkembang biak. Alikodra (2010) menyatakan bahwa letak geografis kawasan sangat mempengaruhi jumlah jenis penghuninya. Sementara Jeffries (1997) menyatakan factor yang juga mempengaruhi tinggi rendahnya keanekaragaman adalah luas dan keberagaman habitat. Putra et al., (2017) mengemukakan bahwa indeks keannekaragaman yang rendah itu diakibatkan karena suatu habitat yang kurang mendukung berbagai aktifitas dan mampu memberikan tempat yang nyaman untuk berlindung dan berkembang biak.

Tabel 3. Pengukuran faktor abiotik

\begin{tabular}{llcccc}
\hline \multirow{2}{*}{ No } & \multirow{2}{*}{ Parameter } & \multicolumn{3}{c}{ Nilai Pengukuran } \\
\cline { 2 - 5 } & & Persawahan & Sungai & Danau & Hutan \\
\hline 1. & Suhu udara rata-rata $\left({ }^{\circ} \mathrm{C}\right)$ & 28 & 30 & 28 & 25 \\
2. & Kelembaban udara rata-rata $(\%)$ & 70 & 60 & 70 & 75 \\
\hline
\end{tabular}

Pengukuran faktor abiotik yang maliputi suhu udara dan kelembaban udara di lokasi penelitian. Suhu udara tercatat berkisar $25^{\circ} \mathrm{C}-30^{\circ} \mathrm{C}$, dengan nilai rata-rata $28^{\circ} \mathrm{C}$. Pada kisaran suhu antara $25^{\circ} \mathrm{C}-30^{\circ} \mathrm{C}$ tersebut memungkinkan bagi jenis reptil untuk hidup dan beraktivitas. Hal ini sejalan dengan pernyataan Silalahi et al., (2015) yang menyatakan bahwa kisaran suhu yang mematikan herpetofauna termasuk reptil adalah $38-42^{\circ} \mathrm{C}$. Suhu udara lingkungan merupakan salah satu hal yang sangat mempengaruhi hewan reptil (Bickford et al., 2010). Sedangkan kelembaban udara diperoleh sebesar $65-75 \%$ dengan nilai rata-rata $69 \%$. Dengan kisaran udara tersebut reptil mampu hidup dan beradaptasi dengan baik terutama bagi kehidupan reptile jenis Python. Faktor lain yang mendukung kehidupan reptile ialah adanya aliran sungai, danau yang mendukung hewan ini tumbuh dan berkembang. Reptil secara umum sangat bergantung pada kelembaban dan ketersediaan air dan seringkali beberapa jenis reptile ditemui tidak jauh dari badan air (sungai, kolam, rawa) (Matswapati, 2009). 


\section{KESIMPULAN}

Ditemukan sebanyak 10 spesies reptil yang termasuk kedalam 8 famili dan 2 ordo dengan jumlah individu sebanya 79 individu. Spesies yang paling banyak ditemukan adalah $M$. multifasciata sedangkan spesies reptilia paling sedikit ditemukan yaitu $P$. reticulatus. Indek keanekaragaman jenis hewan reptilia di Kecamatan Seginim yaitu sebesar 0,823 dalam kategori rendah yang menunjukkan adanya tekanan terhadap habitat dan populasi reptil tidak seimbang.

\section{UCAPAN TERIMA KASIH}

Penulis ucapkan terimakasih kepada bapak Kepala Lembaga Penelitian dan Pengabdian Masyarakat Universitas Muhamamdiyah Bengkulu yang telah memberikan stimulasi, respon, dan motivasi kepada penulis dalam menulis artikel ini. Juga pihak Konservasi Sumber Daya Alam Propinsi Bengkulu dan Semua pihak yang telah membantu yang tidak tersebut satu persatu.

\section{REFERENSI}

Alikodra, H. S. 2010. Pengelolaan Satwa Liar Dalam Rangka Mempertahankan Keanekaragaman Hayati Indonesia. Institut Pertanian Bogor Press. Bogor. 163 hal.

Amri, S., Nurdjali, B., dan Siahaan, S. 2015. Keanekaragaman Jenis Reptil Ordo Squamata Dikawasan Hutan Lindung Gunung Semahung Desa Sebatih Kecamatan Sengah Temila Kabupaten Landak. Jurnal Hutan Lestari, 3(1) : 30-34.

Andin, M. 2010. Ensiklopedia Biologi Dunia Hewan. Jilid 4. PT Lentera Abadi. Jakarta. 562 Hal.

Ario, A. 2010. Panduan Lapangan Mengenal Satwa Taman Nasional Gunung Gede Pangrango. Conservation International Indonesia. Perpustakaan Nasional. Jakarta. 101 Hal.

Bickford, D., Howard, S.D., Ng, D.J.J., and Sheridan, J.A. 2010. Impacts of Climate Change on The Amphibians and Reptiles of South Asia. Biodiversity and Conservation, 4(19): 10431062.

Campbell, N. A., dan Reece, J, B., 2010. Biologi. Jilid 2.Edisi 8. (Terjemanahan D.T. Wulandari) Erlangga. Jakarta. 569 Hal.

Findua, A.W., Harianto S.P., dan Nurchayani, N. 2016. Keanekaragaman Reptil di Repong Damar Pekon Pahmungan Pesisir Barat (Studi Kasus Plot Permanen Universitas Lampung). Sylva Lestari, 4(1): 57-60.

Irham, M. 2012. Fauna Indonesia. Bidang Zoologi Pusat Biologi-LIPI. Jakarta. 43 Hal.

Iskandar, D.T. 2000 Kura-kura dan Buaya, Indonesia dan Papua Nugini. Palmedia Citra. Bandung. $191 \mathrm{Hal}$.

Jeffries, M.J. 1997. Biodiversity And Conservation. Routledge, London. 43 pp.

Juniarmi, R., dan Zakaria, I. 2014. Kepadatan Populasi Distribusi Kadal (Mabouya multifasciata) di Pulau Kecil Kota Padang. Universita Andalas. Sumatera Barat. Jurnal Universita Andalas, 3(1): 51-56

Lisa, R. 2011. Jenis-Jenis Reptilia (Sub Bangsa Lacertilia) di Bukit Sulap Kota Lubuk Linggau Provinsi Sumatera Selatan dan Sumbangannya pada Pembelajaran Biologi di SMA. (Skripsi). Pendidikan Biologi FKIP Universitas Sriwijaya. Palembang. 
Martiva, M., Linna., F, dan Widya, M. 2016. Study Morfometrik Jenis Kura-Kura Air Tawar dan Terestrial di Kelurahan Manguanharjo dan Diiplementasikan Sebagai Boolef. (Repositori) Laporan Penelitian STKIP-PGRI. Lubuk Linggau.

Matswapati, D. 2009. Biologi Reproduksi Ular Sanca Batik (Phyton reticulates). (Skripsi). Institut Pertanian Bogor, Bogor.

Mumpuni. 2001. Keanekaragaman Herpetofauna di Taman Nasional Gunung Halimun Jawa Barat. (Edisi Khusus Biodiversitas Taman Nasional Gunung Halimun) Jurnal Berita Biologi, 5(6): 711-720

Pemerintah Kecamatan Seginim. 2018. Profil Kecamatan Seginim Kabupaten Bengkulu Selatan Propinsi Bengkulu.

Pough, F.H. 1998. Herpetology, Prentice Hall, Inc.New Jersey. 134 Hal.

Putra, A. R., Sudhartono, A., dan Ramlah, S. 2017. Eksplorasi Jenis reptil di Suaka Margasatwa Tanjung Santigi Kabupaten Parigi Moutong. Jurnal Warta Rimba, 5(1) : 87-92.

Silalahi, A., Kusrini, M.D., dan Kartono, A.P. 2015. Karakteristik Mikrohabitat Python reticulates Schnider, 1801 Pada kebun Sagu di Kabupaten Sambas. Jurnal Forest Rehabilitation, 3(1): 1-11.

Subeno. 2018. Distribusi dan Keanekaragaman Herpetofauna di Hulu Sungai Gunung Sindoro Jawa Tengah. Jurnal Ilmu Kehutanan, 12 (1): 40-51.

Subeno, Bayu, WB., dan Jati, A.S. 2010. Distribusi dan Keanekaragaman Herpetofauna Kawasan Tamana Nasional Gunung Merbabu Jawa Tengah. Laporan Penelitian Hibah Dosen Muda Fakultas Kehutanan, Universitas Gadjah Mada. Yogyakarta. (Tidak di Publikasikan).

Rosadi, A.B., Slamet, A., dan Madang, K. 2016. Identifikasi Jenis-Jenis Reptilia di Taman Wisata Alam Bukit Kaba Rejang Lebong Provinsi Bengkulu. Jurnal Pembelajaran Biologi, 4(1): 1-6.

Yanuarefa, M. F., Haryanto, G., dan Utami, J. 2017. Panduan Lapang Herpetofauna (Amfibi dan Reptil) Taman Nasional Alas Purwo. Metode Sampling Bioekologi. Bumi Aksakara. Jakarta. 128 Hal.

\footnotetext{
Authors:

Pariyanto, Program Studi Pendidikan Biologi Fakultas Keguruan dan Ilmu Pendidikan, Universitas Muhammadiyah Bengkulu. Jl. Bali, Kelurahan Kampung Bali, Kecamatan Teluk Segara, Kota Bengkulu. Propinsi Bengkulu, (38119), Indonesia, email: pariyanto@umb.ac.id

Rahmi, Program Studi Pendidikan Biologi Fakultas Keguruan dan Ilmu Pendidikan, Universitas Riau Kepulauan,. Pahlawan No. 99, Propinsi Kepuauan Riau (29422), Indonesia, email: rahmikumbang@gmail.com

Dindi Antarsyah, Program Studi Pendidikan Biologi Fakultas Keguruan dan Ilmu Pendidikan, Universitas Muhammadiyah Bengkulu. Jl. Bali, Kelurahan Kampung Bali, Kecamatan Teluk Segara, Kota Bengkulu. Propinsi Bengkulu, (38119), Indonesia, email: dendiantarsyah570@gmail.com

This is an open-access article distributed under the terms of the Creative Commons Attribution License, which permits unrestricted use, distribution and reproduction in any medium, provided the original author and source are credited. (http://creativecommons.org/licenses/by/4.0/).

\section{How to cite this article:}

Pariyanto, Rahmi, Antarsyah, D. 2020. Diversity of reptile species found in district Seginim Bengkulu Selatan. Simbiosa, 9(2): 90-96. Doi. http://dx.doi.org/10.33373/sim-bio.v9i2.2458
} 